\title{
Multimodality imaging of a left ventricular mass - ECG insights
}

\section{Dear Editor,}

I thank the authors for providing the electrocardiogram (ECG) and the editor for enabling the discussion on this very interesting case.

I want to comment the QRS complex in electrical terms:

*The low QRS voltage seen in the limb leads reflects the reduced active electrical properties of ventricles, and/or the reduced ratio of electrically active myocardium and electrically inactive tissue

(fibrosis?), predominantly in the left ventricle;

*The left axis deviation is consistent with the assumption of the diffuse slowing of conduction velocity in ventricles, predominantly in the left ventricle;

*Fragmented QRS in the aVF lead can result from a local defect of the ventricular activation sequence inferiorly (the apex?);

*The transient zone shifted up to the V6 shows the reduced "electrical dominance" of the left ventricle thus the right ventricle is electrically more "visible".
These findings are consistent with the findings of the imaging methods - of course, the tumor in the cavity cannot be detected by ECG.

Sincerely,

Ljuba Bacharova

International Laser Center, Comenius University, Bratislava, Slovakia

Peer-review: Internal

Conflict of interest: None to declare

Authorship: L.B.

Acknowledgments and funding: None to declare

\section{References}

1.Yakovlev S, Kalinskaya A. Answer to quiz: Multimodality imaging of a left ventricular mass. Heart Vess Transplant 2021; 5: Doi: 10.24969/hvt.2021.286

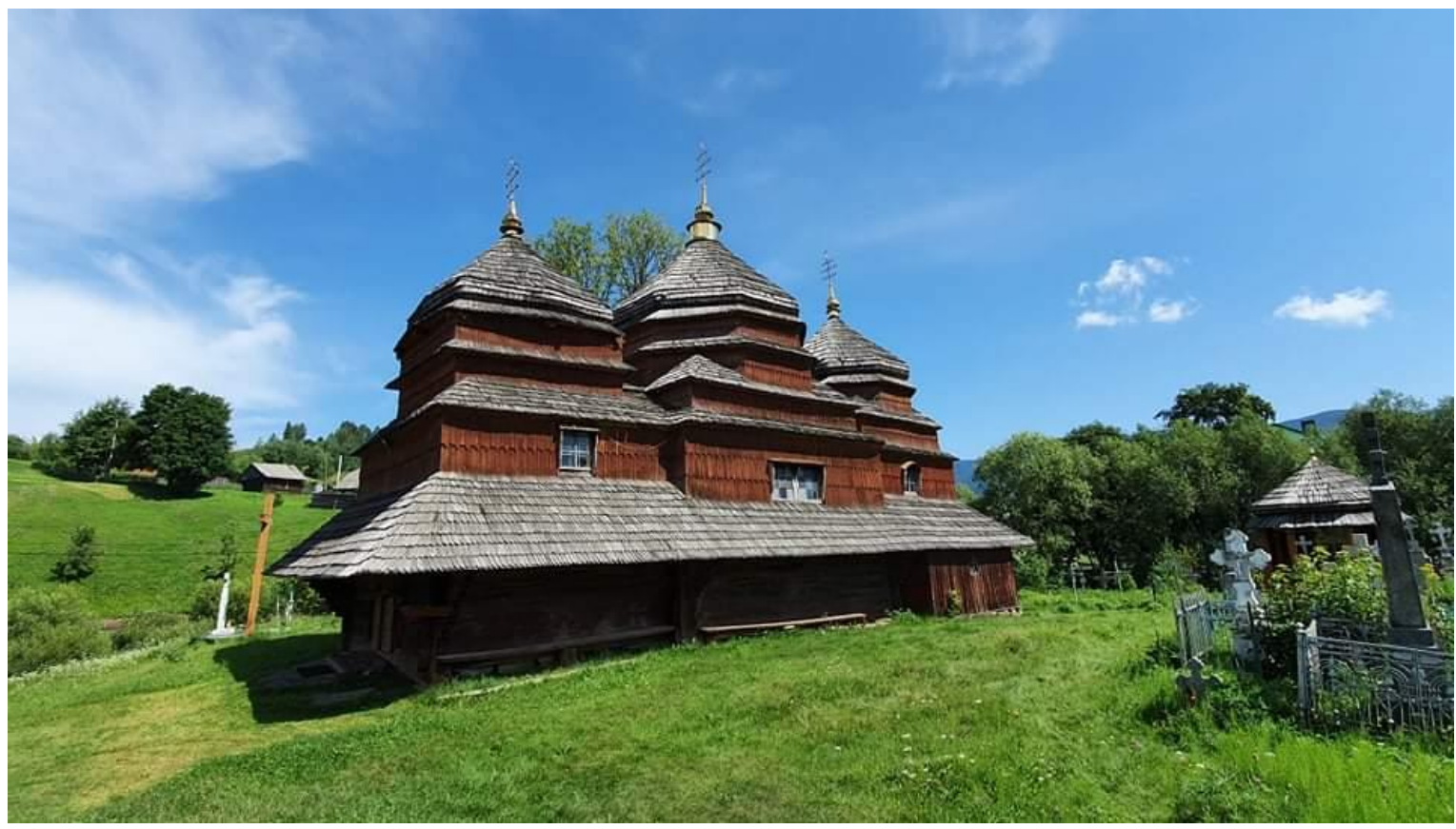

Old wooden church in Carpathian mountains. Yuriy Ivaniv, Lviv, Ukraine

Address for Correspondence: Ljuba Bacharova, International Laser Center, Comenius University, Bratislava, Slovakia Email: Ljuba.Bacharova@cvtisr.com

Received: 24.11.2021 Accepted: 27.11.2021 